\title{
Letras Clássicas
}

\section{ZELIA DE ALMEIDA CARDOSO}

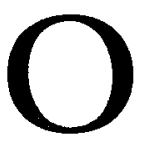

ano de 1971 foi de importância decisiva para os estudos lingüístico-literários sobre a antigüidade greco-latina, na Universidade de Sáo Paulo, por marcar a reestruturação e o reinício do Curso de Pós-Graduação em Letras Clássicas, ministrado na Faculdade de Filosofia, Letras e Ciências Humanas.

Procurado, a partir desse momento, por estudantes recém-formados que pretendiam ampliar seus conhecimentos ou dedicar-se à pesquisa e, sobretudo, por professores de vários pontos do país que já exerciam a docência em escolas de terceiro grau e se viram na contingência de obter titulação adequada para atender a determinações legais, o novo curso thes possibilitou excelentes oportunidades para um frutífero intercâmbio de informaçóes e experiências.

Os estudos clássicos haviam estado presentes na antiga Faculdade de Filosofia, Ciências e Letras, desde a sua fundação. Entre os sete primeiros cursos que começaram a funcionar em julho de 1934, estava o de Letras Clássicas e Português, com suas cadeiras específicas: Filologia Grega e Latina, Literatura Grega, Literatura Latina.

Denominado simplesmente Letras Clássicas a partir de 1939, para adequar-se, por força de lei, aos padróes da Faculdade Nacional de Filosofia, o curso se manteve até o fim dos anos 60, quando o Conselho Federal de Educação reformulou o ensino das Letras no terceiro grau.

Nesse meio tempo, a Universidade de São Paulo, formou numerosos alunos em Letras Clássicas e instituiu cursos de especializaçáo em diversas disciplinas, a serem seguidos por aqueles que postulavam doutoramento. Entre esses cursos estavam os de Língua e Literatura Grega, Língua e Literatura Latina e Glotologia Clássica. Todo esse trabalho tinha evidentemente como objetivo a preservação de um imenso e riquíssimo patrimônio cultural e a colocação desse patrimônio à disposiçáo da sociedade contemporânea.

Em 1969, no entanto, profundas mudanças se operaram na USP. A Faculdade de Filosofia, Ciências e Letras se desmembrou em diversas unidades universitárias e os cursos de graduação em Letras se modificaram em sua estrutura, para atender a prescriçóes federais, abrindo-se em leque e permitindo uma variedade de habilitaçóes, cuja escolha de- 
pendia do aluno. Grego e Latim permaneceram entre as habilitaçóes, mas não lhes foi mais reservado o privilégio de antes, quando se interligavam na composiçăo do cerne de um curso único e preciso em seus objetivos.

A despeito de alguns problemas decorrentes da reforma universitária, a Faculdade de Filosofia, Letras e Ciências Humanas entáo constituída, continuou a formar estudantes que se interessavam pela civilização greco-latina e pelas línguas e literaturas legadas por ela ao mundo moderno. E a reestruturaçăo da pós-graduaçáo, em 1971, como já mencionado, deu nova força a esses estudos.

A estrutura curricular dos cursos previa disciplinas das áreas de concentraçáo e de domínio conexo, operando estas como uma espécie de complemento. Alunos inscritos na pós-graduação em Letras Clássicas tiveram condiçóes de cursar, ao lado das matérias básicas, disciplinas diversas como Lingüística, Edóctica, Teoria Literária, Literatura Comparada, História da Literatura, Filosofia Clássica, História Antiga, Antropologia, Psicologia, História do Teatro e outras tantas. Em contrapartida, alunos que se dedicavam a outros campos do saber matricularam-se em disciplinas constantes da área de Letras Clássicas, o que possibilitou uma desejável interdisciplinaridade. Os estudos sobre a antigüidade puderam valer-se de embasamento científico atualizado e de recursos tecnológicos avançados além de, ao mesmo tempo, aproximarem-se de disciplinas consideradas modernas e constantes de currículos contemporâneos, mas estreitamente vinculadas à cultura antiga.

As línguas clássicas se revelaram como poderoso elemento para alicerçar muitos dos estudos lingüísticos; os textos escritos, examinados em profundidade, mostraram sua importância para análises comparativas e contrastivas não só nos campos da poesia, da narrativa ficcional e do drama mas também da filosofia, da historiografia, da antropologia, da sociologia, da ciência política.

Em 1976, começaram a ser apresentadas as primeiras monografias de mestrado e teses de doutorado de alunos que cursaram a pós-graduaçăo em novas bases; os mestres e doutores em Letras Clássicas então titulados, somaram-se àqueles que haviam obtido títulos análogos por terem defendido seus trabalhos de grau pelo antigo regime vigente na Universidade.

Grande impulso para as pesquisas voltadas à antigüidade ocorreu em 1985, com a fundaçáo de uma sociedade científica a elas consagrada: a Sociedade Brasileira de Estudos Clássicos - SBEC. Entre os sócios fundadores da nova entidade encontravam-se numerosos pesquisadores 
da USP e a primeira presidência foi exercida por docente da Instituição. A fundaçáo da SBEC foi o ponto de partida para a realizaçáo anual de reuniōes científicas, o que possibilitou o encontro de investigadores oriundos de diversas universidades do país - USP, Unicamp, Unesp, UFRJ, UFF, UFMG, UFRGS, UFPR, UFSC, UnB, UFU, UFOP, UFPB, UECE entre outras -, bem como de docentes e pesquisadores do exterior. Travaram conhecimento, nessas reuniōes, pessoas que tinham interesses similares, conquanto por vezes trabalhassem em áreas diferentes como Arqueologia, Antropologia, História, Filosofia, Teatro, Letras. Mais uma vez a interdisciplinaridade foi contemplada, decorrendo evidente enriquecimento para todas as áreas. A filiação da SBEC à FIEC - Fédtration Internationale des Étudtes Classiques - e os convênios firmados com associaçōes latino-americanas ofereceram aos investigadores da USP maiores oportunidades para a divulgação de pesquisas, $O$ intercâmbio cultural e a cooperação científica: aumentaram as possibilidades de participaçăo em reunióes científicas realizadas no país e no exterior, de constituiçăo de grupos de trabalho específicos, de organizaçáo de atividades culturais diversas e de formulação de convites a docentes de outras instituiçóes para ministrarem cursos na Universidade de São Paulo, na qualidade de professores visitantes.

Em 1987, o curso de pós-graduaçăo em Letras Clássicas filiou-se à Anpoll (Associação Nacional de Pós-Graduaçáo e Pesquisa em Letras e Lingǘstica), fundada no ano anterior, e seus docentes propuseram à entidade a criação de um grupo de trabalho que se denominaria Latime grego na universidade brasileira. Criou-se, assim, mais uma oportunidade para a congregaçáo de pesquisadores e a divulgaçáo de trabalhos, e mais um forum para discussóes e debates. Procurando atingir seus objetivos, o GT reuniu-se regularmente todos estes anos, tendo nele sido sempre marcante a presença de professores de Língua e Literatura Grega e Língua e Literatura Latina da Faculdade de Filosofia, Letras e Ciências Humanas.

Ponderando-se todos esses dados, verifica-se que a situação das letras clássicas na USP - e, em decorrência, no próprio país - passou por significativa evoluçáo. $O$ curso de pós-graduaçáo da Faculdade de Filosofia, Letras e Ciências Humanas recebe anualmente alunos novos - incluindo-se entre estes os bolsistas que já exercem a docência em terceiro grau - e tem formado número expressivo de mestres e doutores. Em todos os semestres são ministradas várias disciplinas, ressaltando-se as que têm sido oferecidas por docentes da USP já aposentados, que colaboram com o curso na condiçăo de professores participantes, $\mathrm{e}$ a de professores visitantes, provenientes de universidades e centros de pesquisa do país e do exterior: professores José Riquelme Otálora, da 
Universidade de Saragoça; Mireille Corbier, do Centre de Recherches Scientifiques de Paris; Michele Coccia, da Università de Roma; François Jouan, da Université de Paris; Pedro Paulo Funari, da Unicamp.

Há cerca de dois anos foi instituído o programa de pós-doutorado em Literatura Latina, presentemente com dois doutores inscritos, procedendo a interessantes investigaçóes. Por outro lado, os cursos de graduação em Letras com habilitação em Latim e em Grego prosseguem normalmente, com número regulamentar de alunos; as disciplinas específicas, oferecidas também como optativas a estudantes de outros cursos e Unidades da USP, têm sido bastante procuradas.

No campo da cultura e extensão, as áreas de Língua e Literatura Grega e de Língua e Literatura Latina têm proporcionado à comunidade, desde 1986, cursos de extensáo universitária, que dispóem, atualmente, de algumas vagas reservadas a pessoas de terceira idade. Chama-se a atenção, especialmente, para os cursos básicos de Língua Grega e Língua Latina desenvolvidos em dois anos, em módulos semestrais, e complementados por oficinas de tradução nas quais os alunos entram em contato direto com obras clássicas e preparam textos para a publicação.

Muito bem aceitos, também - contando, por vezes, com mais de uma centena de alunos inscritos - , têm sido os cursos de difusão cultural promovidos anualmente pelas áreas referidas com a finalidade de divulgar aspectos específicos da cultura clássica: teatro greco-latino, manifestaçōes modernas do teatro clássico, a mulher na antigüidade, riso e humor na literatura clássica, concepções do inferno no mundo antigo, temas mitológicos, religiōes antigas, historiografia literária e outros. Tem-se contado, nesses cursos, com a participaçáo de outras áreas do Departamento de Letras Clássicas e Vernáculas (Língua Portuguesa, Literatura Portuguesa, Literatura Brasileira, Língua e Literatura Sânscrita), de outros departamentos (Letras Modernas, História, Antropologia), de outras unidades universitárias (Faculdade de Educação, Instituto de Psicologia, Museu de Arqueologia e Etnologia), e de outras instituiçóes de ensino de terceiro grau (Unicamp, Puccamp, Unesp, UFF).

Vários eventos - congressos, ciclos de conferências e encontros acadêmicos - têm sido promovidos ou co-organizados nos últimos anos pelas áreas de Língua e Literatura Latina e Língua e Literatura Grega. Docentes de ambas as áreas fizeram parte da Comissão Organizadora do II Congresso Nacional de Estudos Clássicos, realizado em 1989, em São Paulo, como atividade conjunta da SBEC e da USP. Evento de grande porte, contou com a presença de mais de quinhentas 
pessoas inscritas, aí somados docentes e pesquisadores do país e do exterior, bem como alunos dos cursos de graduaçăo e pós-gaduaçáo. Para participarem do II Congresso de Estudos Clássicos, cujo tema central era Mito, religino e sociedade, foram convidados conferencistas de renome internacional, como os professores $M$. L. West, da Universidade de Londres; Madeleine Biardeau, da Universidade de Paris; Filippo Coarelli, da Universidade de Perúsia; Olivier Reverdin, da Fundação Hardr; José Nunes Carreira, da Universidade de Lisboa; Alfredo Bosi e Izidoro Blikstein, da USP; José Cavalcante de Souza, da Unicamp; Ciro Flammarion Cardoso, da UFF; Donaldo Schüler, da UFRGS. Foram ministrados, durante o Congresso, diversos cursos de difusão cultural e apresentadas cerca de cento e trinta comunicaçōes científicas, das quais sessenta e duas foram publicadas nas Atas do evento.

Entre os ciclos de conferências, lembramos os que estiveram a cargo de professores visitantes, como Francisco Rodrigues Adrados, do Consejo Superior de Investigaciones de Madrid (atividade promovida em 1988, conjuntamente com o Departamento de História da FFLCH e com o MAE); Arminda Lozano Vellila e Antonio Piñero Saenz, da Unipersidad Complutense de Madrid (atividade promovida em 1988, conjuntamente com os Departamentos de Letras Modernas e de História e o MAE); Claude Mossé e Jean-Claude Gardin, do Instituto de Altos Estudos de Paris (atividade promovida em 1988, conjuntamente com o Departamento de História e o MAE); J. García Moreno, da Universidad de Alcalá de Henares (atividade promovida em 1990, conjuntamente com o Departamento de História); Elisabeth Caballero de del Sastre, da Unipersidad de Buenos Aires (atividade promovida em 1994, com apoio da SBEC). Entre os Encontros Acadêmicos destacamos Jogos Olimpicos: da Grécia Antiga a nossos dias, realizado em 1992, com a colaboraçáo do MAE, da Faculdade de Educaçáo e da Escola de Educação Física da USP; Horacio: dois mil anos e Catulo, um poeta sempre novo, realizados respectivamente em 1992 e 1993, com a colaboraçăo das áreas de Literatura Brasileira e Portuguesa (Departamento de Letras Clássicas e Vernáculas), da área de Língua e Literatura Italiana (Departamento de Letras Modernas) e do CoralUsp.

Em 1994, em conjunto com a SBEC, as áreas de Língua e Literatura Latina e Língua e Literatura Grega realizaram a I Semana Regional de Estudos Cldissicos, focalizando o tema $A$ tradifrio épica no mundo antigo. O evento, do qual participaram docentes e alunos da USP, de outras universidades, e sócios da SBEC, constituiu-se de sessóes de conferências, mesas-redondas, comúnicaçôes e workshops.

Soma-se a todas essas atividades a participação de docentes e alu- 
nos das áreas de Língua e Literatura Latina e de Língua e Literatura Grega, bem como do programa de pós-graduação em Letras Clássicas, em importantes eventos científicos realizados no país (Reunióes Anuais da SBPC e da SBEC, Encontros Nacionais da Anpoll, Seminários do GEL, Congressos promovidos pela Abralic e pela ABA e Semanas de Estudos realizadas pela UFF, UFRJ, UFMG, UFJF, UFCE, UFPR, Unesp, UEM, Unicid, UnG, entre outras) e no exterior (Alemanha, Suíça, França, Grécia, Itália, Espanha, Canadá, Argentina, Uruguai, Venezuela, Cuba).

No campo das publicaçōes, a situação da área de Língua e Literatura Latina e de Língua e Literatura Grega se mostra bastante diferente da que se verificava no passado. Se há alguns anos a produção científica dos pesquisadores só tinha acesso a canais de divulgaçăo nos encontros interpares, hoje, não só há editoras que se interessam pela publicação de trabalhos concernentes aos estudos clássicos - a exemplo de Ática, Mercado Aberto, Ars Poetica, Nova Alexandria, Hucitec, Martins Fontes, Companhia das Letras, Brasiliense e outras -, como também se abrem espaços para os mesmos em revistas literárias e periódicos.

Parece que a sociedade contemporânea despertou para reconhecer o que deve à cultura clássica. Provas contundentes desse reconhecimento estão no elevado número de peças teatrais, com temas clássicos, exibidas constantemente em nossos teatros, no interesse do público por cursos e conferências referentes à antigüidade, sobretudo aos mitos greco-romanos, e no surgimento de grupos de trabalho, de caráter interdisciplinar, que se voltam para o rico manancial deixado por nossos antepassados.

Diante desse panorama destacamos o papel da USP que, em meio a crises e dificuldades, ombreou com as grandes universidades do mundo e não só conservou os cursos e as disciplinas relacionadas com a antigüidade, como lhes ofereceu oportunidades reais para que se desenvolvessem e frutificassem, permitindo que se realizassem pesquisas de alto nível no campo de uma cultura em que estão as raízes da nossa. Reafirmou-se, com isso, que o conhecimento dos valores antigos é poderoso instrumento para a expansão do humanismo e a compreensão do universo cultural que se manifesta no presente.

Zelia de Almeida Cardoso é professora do Departamento de Letras Clássicas e Vernáculas da Faculdade de Filosofia, Letras e Ciências Humanas da USP. 